\title{
Risk perception and correlates of alcohol use among out-of-school youth in motor parks in Lagos State, Nigeria \\ O Dada ${ }^{1}$, Odukoya $\mathrm{O}^{1^{*}}$, K Okuyemi ${ }^{2}$
}

1. Department of Community Health and Primary Care, College of Medicine, University of Lagos, Lagos, Nigeria

2. Department of Family Medicine and Community Health, University of Minnesota, Minneapolis, Minnesota, USA

Correspondence can be addressed: drolukemiodukoya@yahoo.com

\begin{abstract}
\section{Background and Aim}

The prevalence of alcohol use has increased globally. Out-of-school youth are a vulnerable group who might have missed opportunities for learning healthy behaviours in a formal school environment. The purpose of this study was to determine the risk perception, pattern of use, and correlates of alcohol use among out-of-school youth in Lagos, Nigeria.

\section{Methods}

A cross-sectional study was conducted among 380 out-of-school youth in motor parks in Lagos State, Nigeria, using interviewer administered questionnaires.

\section{Results}

The lifetime prevalence of alcohol use was $61.1 \%$, while $55.5 \%$ were current drinkers. Beer $(57.3 \%)$ was the most consumed type of alcohol, followed by distilled spirits (29.8\%). Using the CAGE scoring system, more than half (57.8\%) of the current drinkers had a drinking problem. Almost three quarters (70.1\%) had experienced at least one episode of alcohol intoxication within the past month. A considerable number of current drinkers (63.5\%) desired to reduce their alcohol intake or stop drinking, while $45.5 \%$ had made unsuccessful attempts to do so within the past year. Only $28.9 \%$ had received assistance to quit or reduce their drinking and of these less than half (39.3\%) received assistance from a professional or healthcare worker. Males were more likely to be current drinkers and to have experienced episodes of alcohol intoxication. Parental and peer drinking were associated with alcohol use but not with intoxication.
\end{abstract}

\section{Conclusions}

It is important to design specific programmes to reduce alcohol use among out-of-school youth in these settings.

\section{Introduction}

Harmful use of alcohol causes 3.3 million yearly deaths worldwide, representing $5.9 \%$ of all deaths. ${ }^{1}$ Alcohol plays a causative role in more than 200 disease and injury conditions and $5.1 \%$ of the world's disease and injury burden is attributable to alcohol. ${ }^{1}$ Intoxication, dependence, and other biochemical effects can result in any number of the myriad health and social consequences of alcohol consumption, such as traumatic death and injury (through automobile accidents, for example), chronic liver disease, cancers, cardiovascular disease, acute alcohol poisoning, and foetal alcohol spectrum disorders. ${ }^{2}$ Alcohol consumption tends to cause morbidity and mortality in younger people: approximately $25 \%$ of the total deaths of people 20 to 39 years old are attributable to alcohol. ${ }^{1}$

Many low- and middle-income countries (LMICs), such as Nigeria, lack comprehensive policies regulating the production, marketing, advertising, and availability of alcohol, including satisfactory specific policies guiding these activities in relation to potential young consumers." Nigeria relies on self-regulatory, brewer-sponsored "drink responsibly" campaigns. It has been argued that these campaigns are used as a form of advertisement. ${ }^{3}$ In addition, there is no legal minimum age for drinking in the country, and young people are allowed to buy and sell alcohol. ${ }^{4}$ Few studies have estimated the national prevalence of alcohol use; however, according to the 2003 World Health Organization Gender Alcohol and Culture: An International Study (WHO GENACIS), the rate of alcohol consumption among Nigerian adults was $42.9 \%$ for men and $23 \%$ for women.
More recent but localised studies conducted in 2012 have reported values of $46.7 \%$ among older adults in Plateau State $^{6}$ and 40.9\% among school-going adolescents in Lagos. ${ }^{7}$

Youth is the period of life between childhood and adulthood. ${ }^{8,9}$ This period is usually associated with identity formation: coping with peer pressure and assimilating matters such as lifestyle choices, gender roles, and cultural understanding. The leading causes of morbidity and mortality among adults are related to risky behaviours and behavioural patterns, which are established during youth and extend into adulthood. ${ }^{10}$ The term "out-of-school youth" describes several groups of young people: school dropouts, those who never attended school, and those who participate in no formal school programmes. The term also refers to young people between 15 and 24 years of age who are not enrolled in school, not employed, and not tertiary-level graduates. ${ }^{11}$ Many factors and behaviours associated with adverse health may be more common among out-of-school youth, when compared with their in-school counterparts. ${ }^{12}$

In developed countries, most youth are compulsorily enrolled within the school system. In developing countries like Nigeria, however, this is not always the case. In Nigeria about 10.1 million children who should be enrolled in basic education are not in school. ${ }^{13}$ In other words, nearly onethird of primary school-aged children are out-of-school, and roughly a quarter of junior secondary school-aged children do not complete 12 years of formal education.

Most studies assessing alcohol use among youth have focused on youth within formal school settings, ignoring or excluding their out-of-school counterparts. Therefore, there are limited 
empirical data on the pattern and correlates of alcohol use among out-of-school youth in Nigeria. ${ }^{14-16}$ This study set out to determine the knowledge, attitudes, and patterns of alcohol use among this vulnerable group of young people, who are often neglected in the research, planning, and implementation of programmes.

\section{Methods \\ Study setting}

Lagos State, one of the 36 states in Nigeria, is located in the southwestern part of the country. It is one of the most densely populated and cosmopolitan states in the country, and within its borders is the city of Lagos, which is the commercial capital of Nigeria and the most populous city in Africa. In the state, as well as in urban centres throughout Nigeria, the National Union of Road and Transport Workers (NURTW) oversees some of the activities that take place within motor parks and garages, including basic transportation and commercial activities. Commuters and travellers use these motor parks as points of contact with public transportation services. Out-of school youth also tend to congregate in these public spaces, usually without adult supervision. Within the motor parks and garages, youth can often be found either engaging in menial labour, or simply loitering and spending time with friends. Illegal activities, as well as alcohol and illicit drug use are also prevalent in this environment.

\section{Study design and sampling}

This was a cross-sectional study, which used a two-stage sampling technique to select participants, aged 15 to 24 years, found in garages or motor parks during normal school hours. A minimum sample size of 361 was estimated using the formula $\mathrm{n}=\mathrm{z} 2 \mathrm{pq} / \mathrm{d} 2$ and a $37.8 \%$ prevalence (extracted from a previous study ${ }^{17}$ ) of alcohol use among youth. Allowing for a non-response rate of $5 \%$, the minimum sample size was increased to 380. Four motor parks (Ojuelegba, Ojota, Oshodi, and Obalende) were selected by simple random sampling from the list of 18 major motor parks, and all eligible and consenting participants were included in the survey. Eligible participants were aged between 10 and 24 years and not currently enrolled in a formal schooling system. Before administration of the questionnaires, information on each respondent's age and school attendance was obtained verbally and ineligible individuals were excluded. A total of 380 respondents were sampled.

\section{Questionnaire and interviews}

The questionnaire used to interview the participants was prepared as an adaptation of the CAGE questionnaire on alcohol use, ${ }^{18}$ the World Health Organization (WHO) guidelines for substance abuse ${ }^{19}$ and from further review of the existing literature. The questionnaire contained sections on sociodemographic data, knowledge regarding alcohol use, attitudes towards alcohol use, and patterns of alcohol use. Trained research assistants administered the questionnaires, and each interview took about 15 minutes to complete.

\section{Ethical considerations}

Prior to the study, ethical approval was obtained from the Ethical Review Board of the Lagos University Teaching Hospital and permission was also obtained from the union leaders in the motor parks. Eligible participants were assured of the voluntary and confidential nature of the study, and written informed consent was obtained from all participants.

\section{Data analysis}

The data were analysed using Epi Info 3.5 and SPSS 16.0 software. A scoring system was developed by the researchers to score the respondents' knowledge and attitudes towards alcohol use, as no known validated scoring systems exist on this topic in our environment. There were ten questions assessing the respondents' knowledge of alcohol use and its health-related risks. Each correct answer corresponded to a score of one point and an incorrect answer corresponded to a score of zero. These scores were summed up and converted into percentages. Respondents with percentages ranging from $0 \%$ to $40 \%$ were classified as having poor knowledge, those with values between $40 \%$ and $60 \%$ were classified as fair, while those above $60 \%$ were classified as having good levels of knowledge. Questions about attitudes towards alcohol use were assessed using a three-point Likert scale: two points were given for the most positive answer and zero points for the most negative answer to each question. The highest "attitude score" obtainable was 16 points, and these scores were also converted into percentages. Respondents with percentages less than or equal to $50 \%$ were classified as having negative attitudes towards alcohol use, while percentages above 50\% corresponded with positive attitudes. The CAGE assessment of problem drinking was used to determine respondents who were problem drinkers. ${ }^{18}$ Developed by Dr. John Ewing, the CAGE questionnaire is an internationally used screening instrument for identifying problem drinking and potential alcoholism. There are four CAGE questions. Respondents who answered in the affirmative to two or more of the four questions were categorised as problem drinkers.

Univariate analysis was carried out using frequency tables, means, standard deviations, and percentages. Current drinking was assessed with questions on self-reported current drinking status and consumption of alcohol within the past 30 days. Respondents who answered in the affirmative to the question "Have you ever been intoxicated with alcohol within the past 12 months" were considered to have had at least one episode of alcohol intoxication. Thereafter, bivariate analysis was carried out on both variables using chi-square tests and t-tests, as appropriate. Two separate regression models were developed: one assessed the factors associated with current drinking and the other assessed the factors associated with alcohol intoxication. In developing each model, variables that were statistically significant on the bivariate analysis were included in the regression model, using a block entry approach, after controlling for tobacco and marijuana use. All input variables were checked for multicollinearity and homoscedasticity. P values $\leq 0.05$ were considered statistically significant.

\section{Results}

\section{Sociodemographic characteristics}

Table 1 shows that the respondents' ages ranged from 15 to 24 years, with $124(32.6 \%)$ of the respondents aged between 23 and 24 years of age. The mean age of the respondents was $21.0 \pm 2.3$ years. Of the 380 participants, $310(81.6 \%)$ were male. The majority of respondents, 354 (93.2\%), had attended some form of formal schooling in the past; 295 $(83.3 \%)$ of these dropped out of school before Senior Secondary Class 3 (SS3, the Nigerian equivalent of grade 12). The mean age among the school dropouts was 15.8 \pm 2.9 years. Among 331 respondents with formal living arrangements, $102(30.8 \%)$ lived alone, while $29.3 \%$ and 
$12.4 \%$ lived with (either or both) parents and other relatives, respectively. A total of 172 respondents $(45.3 \%)$ earned incomes less than 5000 Nigerian Naira $(\mathrm{N}$, approximately US\$29), while only $3(0.9 \%)$ earned incomes above N30,000 (approximately \$176) per week (the average weekly income in Nigeria is approximately N12,660 or $\$ 74) .{ }^{20}$ Almost half of the respondents $(\mathrm{n}=179 ; 47.1 \%)$ had at least one family member who consumed alcohol, $71.1 \%$ had close friends who consumed alcohol, and $18.1 \%$ had a role model who consumed alcohol.

Table 1: Sociodemographic characteristics of study participants

\begin{tabular}{|c|c|}
\hline Sociodemographic variables $(\mathrm{N}=\mathbf{3 8 0})$ & Frequency $(\%)$ \\
\hline \multicolumn{2}{|l|}{ Age range (years) } \\
\hline $15-16$ & $19(5.0)$ \\
\hline $17-18$ & $36(9.5)$ \\
\hline $19-20$ & $107(28.2)$ \\
\hline $21-22$ & $94(24.7)$ \\
\hline $23-24$ & $124(32.6)$ \\
\hline Mean age \pm standard deviation (SD) & $21.0 \pm 2.3$ \\
\hline \multicolumn{2}{|l|}{ Gender } \\
\hline Male & $310(81.6)$ \\
\hline Female & $70(18.4)$ \\
\hline \multicolumn{2}{|l|}{ Religion } \\
\hline Islam & $148(39.4)$ \\
\hline Christianity & $228(59.8)$ \\
\hline Others' & $3(0.8)$ \\
\hline \multicolumn{2}{|l|}{ Ever attended formal schooling } \\
\hline Yes & $354(93.2)$ \\
\hline No & $26(6.8)$ \\
\hline \multicolumn{2}{|l|}{ Highest level of education } \\
\hline None & $26(6.8)$ \\
\hline Primary & $65(17.1)$ \\
\hline Secondary & $289(76.0)$ \\
\hline \multicolumn{2}{|c|}{ Level of education at school dropout ( $\mathrm{n}=354)$} \\
\hline Year 1 to 6 & $65(18.4)$ \\
\hline Year 7-9 & $101(28.6)$ \\
\hline Year $10-12$ & $188(53.1)$ \\
\hline Mean age of school dropout \pm SD & $15.8 \pm 2.9$ \\
\hline \multicolumn{2}{|c|}{ Living arrangement (respondent resides with:) } \\
\hline One or both parents & $41(12.4)$ \\
\hline Other relative & $97(29.3)$ \\
\hline Friends & $91(27.5)$ \\
\hline Alone & $102(30.8)$ \\
\hline Othersb & $49(12.9)$ \\
\hline Family member drinks alcohol & $179(47.1)$ \\
\hline Close friend drinks alcohol & $270(71.1)$ \\
\hline Role model drinks alcohol & $69(18.2)$ \\
\hline
\end{tabular}

sIncludes identification with both Islam and Christinnity, paganism, and no religion

bIncludes garage, boss, under the bridge

\section{Knowledge regarding alcohol use}

Table 2 shows that $352(92.6 \%)$ of the respondents were aware of the harmful effects of alcohol and that $306(82.9 \%)$ of the respondents were aware that it is not safe to drive a vehicle after consuming alcohol. A total of 357 respondents $(93.7 \%)$ were aware that alcohol is associated with road traffic accidents, 299 (78.7\%) were aware of alcohol's association with liver disease, $192(50.5 \%)$ with cancer, and 251 (66.1\%) with heart disease, as shown in Table 2.

\section{Attitudes and perceptions regarding alcohol use}

Table 2 also shows that 328 participants $(86.3 \%)$ agreed that alcohol use among youth is a serious problem. Drinking and driving was identified as a serious problem by 329 respondents $(86.6 \%)$. There were 196 respondents $(51.6 \%)$ who held the opinion that alcohol helps boost one's reputation; 130 $(34.2 \%)$ of the respondents believed that people who drink alcohol have more friends; 119 (31.1\%) believed that without alcohol, a social gathering is incomplete; and 301 (79.2\%) respondents were of the opinion that persons below 18 years of age should be restricted from purchasing alcohol. An assessment of the respondents' perceptions of the reasons for youth drinking revealed that about half $(47.9 \%)$ thought that young people who drink do so because they want to have a good time at a party, while $45.8 \%$ believed they drink because they want to fit in or be accepted by friends.

\section{Pattern of alcohol use and CAGE assessment of alcohol dependence}

Table 3 shows that the lifetime prevalence of alcohol use among the respondents was $61.1 \%$ and that $211(55.5 \%)$ are current drinkers. Of the current drinkers, 147 (69.7\%) consumed alcohol frequently, 53 (25.1\%) occasionally, and $11(5.2 \%)$ rarely consumed alcohol. There were 171 current drinkers $(81.0 \%)$ who had consumed alcohol in the week preceding the survey. With $98(57.3 \%)$ respondents indicating consumption of it, beer was the most commonly consumed type of alcohol, followed by distilled spirits, which was indicated as consumed by 51 participants (29.8\%). The reasons given for taking alcohol varied: 98 respondents $(47.1 \%)$ said they drank because they want to relieve stress, $84(40.4 \%)$ drank for the fun of it, and $22(10.6 \%)$ because of peer pressure.

Using the CAGE questionnaire to assess alcohol dependence, $108(51.2 \%)$ respondents felt that they needed to cut down on their drinking, $88(41.7 \%)$ said they had been annoyed by others' criticism of their drinking, $102(48.3 \%)$ had felt guilty about their drinking, and $57.8 \%$ had previously felt they needed to take a drink early in the morning. According to the CAGE responses, more than half $(57.8 \%)$ of the current drinkers had a drinking problem.

Almost three quarters $(70.1 \%)$ of the drinkers had at least one episode of alcohol intoxication within the past month, and the number of drunken episodes ranged from 1 to 20 episodes, with a median of 2 drunken episodes in the previous month. Nearly half $(45.0 \%)$ of the current drinkers admitted to drinking alcohol before or during sexual intercourse. There were 134 current drinkers $(63.5 \%)$ who expressed a desire to stop drinking, while $96(45.5 \%)$ had made unsuccessful attempts to stop drinking within the past year, and $66(31.1 \%)$ did not think that they would be able to stop drinking without external assistance. Only 61 (28.9\%) of the current drinkers had ever received any assistance with cessation of alcohol consumption; such assistance was 
primarily provided by family members, friends, and, to a slightly lesser extent, healthcare workers.

Table 2: Respondents' knowledge and attitudes regarding alcohol consumption

\begin{tabular}{lcc}
\hline \multicolumn{1}{c}{ Respondent perception (N - 380) } & Frequency (\%) \\
\hline Alcohol is harmful to health & $352(92.6)$ \\
It is not safe to drive a car after talding alcoholic drinks & $306(82.9)$ \\
Alcohol use among youth is a serious problem & & \\
& Agree & $328(86.3)$ \\
& Uncertain & $20(5.3)$ \\
& Disagree & $32(8.4)$
\end{tabular}

Drinking and driving among youth is a serious problem

$\begin{array}{rc}\text { Agree } & 329(86.6) \\ \text { Uncertain } & 12(3.2) \\ \text { Disagree } & 39(10.3)\end{array}$

Alcohol helps boost oae's reputation

$\begin{array}{rc}\text { Agree } & 196(51.6) \\ \text { Uncertain } & 30(7.9) \\ \text { Disagree } & 154(40.5)\end{array}$

Youth who drink have more friends

$\begin{array}{rr}\text { Agree } & 130(34.2) \\ \text { Uncertain } & 47(12.4) \\ \text { Disagree } & 203(53.4)\end{array}$

Without alcobol, a social gathering is incomplete

$\begin{array}{rc}\text { Agree } & 119(31.1) \\ \text { Uncertain } & 20(5.3) \\ \text { Disagree } & 241(64.3)\end{array}$

Sales of alcohol should be restricted to persons below 18 years of age

Agree 301 (79.2)

Uncertain $25(14.2)$

Disagree $54(6.6)$

Why young people drink alcohol

$$
\begin{array}{rc}
\text { They are sad or depressed } & 303(79.7) \\
\text { They wish to rebel against authority } & 17(4.5) \\
\text { Peer pressure } & 174(45.8) \\
\text { Boredom } & 118(31.1) \\
\text { They wish to have a good time at a party } & 182(47.9)
\end{array}
$$

\begin{tabular}{|c|c|}
\hline Variables & Frequency $(\%)$ \\
\hline \multicolumn{2}{|l|}{ Lifetime alcohol consumption $(\mathrm{N}=380)$} \\
\hline Never consumed & $148(38.9)$ \\
\hline Ever consumed & $232(61.1)$ \\
\hline Current consumption & $211(55.5)$ \\
\hline Previous consumption but stopped & $21(5.5)$ \\
\hline $\begin{array}{l}\text { Mean age at alcohol initiation } \pm \\
\text { standard deviation }\end{array}$ & $13.0 \pm 2.4$ \\
\hline \multicolumn{2}{|l|}{ Frequency of alcohol consumption $(n=211)$} \\
\hline Frequently & $147(69.7)$ \\
\hline Occasionally & $53(25.1)$ \\
\hline Rarely & $11(5.2)$ \\
\hline Consumed alcohol in the past 7 days $(n=211)$ & $171(81.0)$ \\
\hline \multicolumn{2}{|l|}{$\begin{array}{l}\text { Types of alcohol consumed (multiple responses allowed } \\
\text { for one respondent) }\end{array}$} \\
\hline Beer & $98(46.4)$ \\
\hline Alomo* & $43(20.4)$ \\
\hline Wine & $2(0.9)$ \\
\hline Spirits & $51(24.2)$ \\
\hline \multicolumn{2}{|l|}{ Primary reasons for drinking $(n=211)$} \\
\hline Fun & $84(39.8)$ \\
\hline Stress relief & $98(46.4)$ \\
\hline Peer pressure & $22(10.4)$ \\
\hline Others & $12(5.7)$ \\
\hline \multicolumn{2}{|l|}{ CAGE questionnaire responses $(n=211)$} \\
\hline Ever felt the need to cut down or reduce drinking & $108(51.2)$ \\
\hline Ever annoyed by someone criticizing your drinking & $88(41.7)$ \\
\hline Ever felt bad or guilty after drinking & $102(48.3)$ \\
\hline Ever felt the need for an early-morning drink (eye-opener) & $77(36.5)$ \\
\hline Problem drinker $(n=211)$ & $122(57.8)$ \\
\hline Had at least one drunken episode in the past month & $148(70.1)$ \\
\hline Ever used alcohol just before or during sexual intercourse & $95(45.0)$ \\
\hline Willing to quit drinking $(\mathrm{n}=\mathbf{2 1 1})$ & $134(63.5)$ \\
\hline Attempted to quit within the past year $(n=211)$ & $96(45.5)$ \\
\hline Perceived ability to quit drinking $(\mathrm{n}=211)$ & $145(68.7)$ \\
\hline $\begin{array}{l}\text { Ever received assistance in attempts to reduce or quit } \\
\text { drinking }(\mathrm{n}=211)\end{array}$ & $61(28.9)$ \\
\hline Assistance from: & \\
\hline Professional or healthcare worker & $24(39.3)$ \\
\hline Family member & $26(42.6)$ \\
\hline Friend & $25(40.9)$ \\
\hline
\end{tabular}

Knowledge of potential consequences of excessive alcohol consumption

$$
\begin{array}{rr}
\text { Road traffic accidents } & 357(93.7) \\
\text { Liver disease } & 299(78.7) \\
\text { Cancer } & 192(50.5) \\
\text { Heart disease } & 251(66.1) \\
\text { Sudden death } & 252(66.3) \\
\text { Alochol poisoning } & 268(70.5) \\
\text { Unwanted/unprotected sex } & 215(56.6) \\
\text { Violence } & 352(92.6)
\end{array}
$$

Table 3: Alcohol use patterns among study participants

${ }^{*}$ Alomo is a widely available commercially produced alcoholic beverage that is popular in Nigeria

\section{Factors associated with alcohol use among the respondents}

Bivariate analysis showed that a higher percentage of males $(62.9 \%)$ than females $(22.9 \%: \mathrm{P}<0.001)$ were current drinkers. Similarly, age, income, attitudes towards drinking, and living arrangements were also statistically significantly associated with current drinking. There were also significantly more drinkers among those participants whose parents, other family members, close friends, or role models consumed alcohol. There was, however, no significant association between knowledge of the respondents and use of alcohol. Alcohol intoxication, on the other hand, varied significantly 
by respondent gender, knowledge and attitude scores, history of enrolment in formal education, and motor park location.

Multivariate analysis showed that being male (odds ratio $[\mathrm{OR}]=3.15, \mathrm{P}=0.003)$; having parents who drink (OR = $2.39, \mathrm{P}=0.011)$; having other family members who drink $(\mathrm{OR}=2.05, \mathrm{P}=0.031)$; and having close friends who drink (OR 7.42, P < 0.001) were statistically significantly associated with current alcohol consumption. In addition, respondents with more positive attitudes towards alcohol consumption were 0.86 times as likely to be current drinkers as those with negative attitudes $(\mathrm{P}=0.025)$. The correlates of alcohol intoxication included being male $(\mathrm{OR}=21.29, \mathrm{P}<0.001)$ and having ever attended formal schooling $(\mathrm{OR}=17.18, \mathrm{P}$ $=0.032$ ). Respondents who were found in the motor park in Ojuelegba were 0.216 times as likely to have been intoxicated as those in Obalende $(\mathrm{P}=0.006)$.

Table 4: Bivariate analysis of factors associated with current drinking and history of intoxication

\begin{tabular}{|c|c|c|c|c|c|c|}
\hline \multirow{2}{*}{$\begin{array}{l}\text { Respondent } \\
\text { characteristics }\end{array}$} & \multicolumn{2}{|c|}{$\begin{array}{l}\text { Frequency }(\%) \text { or mean } \pm \\
\text { standard deviation }(\mathrm{SD})\end{array}$} & \multirow{2}{*}{ P value } & \multicolumn{2}{|c|}{$\begin{array}{l}\text { Frequency (\%) } \\
\text { or mean } \pm S D\end{array}$} & \multirow{2}{*}{$P$ value } \\
\hline & $\begin{array}{l}\text { Current drinkers } \\
\quad(\mathrm{n}=211)\end{array}$ & $\begin{array}{l}\text { Non-drinkers } \\
(\mathrm{n}=169)\end{array}$ & & $\begin{array}{c}\text { Ever been } \\
\text { intoxicated } \\
(\mathrm{n}=148)\end{array}$ & $\begin{array}{c}\text { Never been } \\
\text { intoxicated } \\
(\mathrm{n}=63)\end{array}$ & \\
\hline Mean age (years) & $21.3 \pm 2.0$ & $20.5 \pm 2.6$ & 0.002 & $21.3 \pm 2.0$ & $21.4 \pm 2.1$ & 0.686 \\
\hline \multicolumn{7}{|l|}{ Gender } \\
\hline Female & $16(22.9)$ & $54(77.1)$ & \multirow{2}{*}{$<0.001$} & $4(25.0)$ & $12(75.0)$ & \multirow{2}{*}{$<0.001$} \\
\hline Male & $195(62.9)$ & $115(37.1)$ & & $144(73.8)$ & $51(26.2)$ & \\
\hline \multicolumn{7}{|l|}{ Religion } \\
\hline Christianity & $122(52.8)$ & $109(47.2)$ & \multirow{2}{*}{0.205} & $87(71.3)$ & $35(28.7)$ & \multirow{2}{*}{0.761} \\
\hline Islam & $89(59.7)$ & $60(40.3)$ & & $61(68.5)$ & $28(31.5)$ & \\
\hline \multicolumn{7}{|l|}{ Ever attended school } \\
\hline Yes & $195(55.1)$ & $159(44.9)$ & \multirow{2}{*}{0.548} & $15(93.8)$ & $1(6.3)$ & \multirow{2}{*}{0.043} \\
\hline No & $16(61.5)$ & $10(38.5)$ & & $133(68.2)$ & $62(31.8)$ & \\
\hline $\begin{array}{l}\text { Mean years of } \\
\text { formal schooling }\end{array}$ & $9.0 \pm 3.2$ & $9.0 \pm 3.1$ & 0.969 & $8.0 \pm 3.5$ & $9.6 \pm 2.7$ & 0.126 \\
\hline $\begin{array}{l}\text { Mean age at school } \\
\text { dropout (years) }\end{array}$ & $16.0 \pm 2.7$ & $15.5 \pm 3.1$ & 0.127 & $16.0 \pm 2.8$ & $16.1 \pm 2.6$ & 0.765 \\
\hline \multicolumn{7}{|l|}{$\begin{array}{l}\text { Respondent lives } \\
\text { with }\end{array}$} \\
\hline Family member & $63(45.7)$ & $75(54.3)$ & \multirow{2}{*}{0.004} & $32(50.8)$ & $31(49.2)$ & \multirow{2}{*}{$<0.001$} \\
\hline Alone or with friends & $148(61.2)$ & $94(38.8)$ & & $116(78.4)$ & $32(21.6)$ & \\
\hline $\begin{array}{l}\text { Mean weekly } \\
\text { income (US\$) }\end{array}$ & $9.5 \pm 6.7$ & $6.8 \pm 4.7$ & $<0.001$ & $9.51 \pm 5.1$ & $9.48 \pm 9.4$ & 0.973 \\
\hline Parent drinks & 83 (77.6) & $24(22.4)$ & $<0.001$ & $56(67.5)$ & $27(32.5)$ & 0.539 \\
\hline $\begin{array}{l}\text { Other family } \\
\text { member drinks }\end{array}$ & $84(77.1)$ & $25(22.5)$ & $<0.001$ & $57(67.9)$ & $27(32.1)$ & 0.645 \\
\hline Close friend drinks & $195(72.2)$ & $75(27.8)$ & $<0.001$ & $139(71.3)$ & $56(28.7)$ & 0.256 \\
\hline Role model drinks & $54(78.3)$ & $14(21.7)$ & $<0.001$ & $148(70.1)$ & $63(29.9)$ & 0.120 \\
\hline $\begin{array}{l}\text { Mean knowledge } \\
\text { score }\end{array}$ & $7.47 \pm 2.1$ & $7.59 \pm 2.6$ & 0.613 & $7.26 \pm 2.2$ & $7.97 \pm 1.7$ & 0.022 \\
\hline Mean attitude score & $8.45 \pm 2.3$ & $9.83 \pm 2.3$ & $<0.001$ & $8.21 \pm 2.2$ & $9.0 \pm 1.9$ & 0.017 \\
\hline \multicolumn{7}{|l|}{ Motor park location } \\
\hline Obalende & $48(47.5)$ & $53(52.5)$ & \multirow{4}{*}{0.040} & $36(75.0)$ & $12(25.0)$ & \multirow{4}{*}{0.004} \\
\hline Ojota & $64(63.4)$ & $37(36.6)$ & & $34(53.1)$ & $30(46.9)$ & \\
\hline Ojuelegba & $61(62.9)$ & $36(37.1)$ & & $47(77.0)$ & $14(23.0)$ & \\
\hline Oshodi & $38(46.9)$ & $43(53.1)$ & & $31(81.6)$ & $7(18.4)$ & \\
\hline
\end{tabular}

\section{Discussion}

The harmful use of alcohol is associated with several adverse health outcomes. In this study, we observed that the prevalence of alcohol consumption was high. Lifetime prevalence was $61.1 \%$ and the majority of the young people had progressed to become regular drinkers. Using the CAGE assessment, many of the study participants had a drinking problem. Only a limited number of related studies have been carried out in this population, so opportunities for direct comparisons are limited. One study, conducted among adolescents in vulnerable environments in five different world cities, also cited alcohol use as a common problem. ${ }^{21}$ Studies in Nigeria conducted among participants of similar ages but within formal school settings show comparatively lower proportions of alcohol consumption. ${ }^{14-16}$ Our figures are also higher than values reported among Nigerian adults in the general population. ${ }^{5}$ Being outside of a formal school environment, out-of-school youth are particularly vulnerable to the pressures associated with identity formation and may miss out on opportunities for learning healthful behaviours in a conducive environment, ${ }^{12}$ and this may be responsible for the high figures observed. In dealing with the problems of alcohol use in Nigeria, specifically tailored control strategies for young people outside of formal school settings, such as in motor parks, need to be developed.

Table 5: Determinants of alcohol consumption and intoxication among study participants

\begin{tabular}{|c|c|c|c|c|c|c|}
\hline \multirow[b]{2}{*}{$\begin{array}{l}\text { Respondent } \\
\text { characteristics }\end{array}$} & \multicolumn{2}{|c|}{ Alcohol consumption } & \multirow[b]{2}{*}{ P value } & \multicolumn{2}{|c|}{ Alcohol Intoxication } & \multirow[b]{2}{*}{ P value } \\
\hline & $\begin{array}{l}\text { Adjusted } \\
\text { OR }\end{array}$ & $95 \% \mathrm{CI}$ & & $\begin{array}{l}\text { Adjusted } \\
\text { OR }\end{array}$ & $95 \% \mathrm{CI}$ & \\
\hline Age & 1.03 & $0.92-1.17$ & 0.587 & & & \\
\hline \multicolumn{7}{|l|}{ Gender } \\
\hline Female & 1 & & & 1 & & \\
\hline Male & 3.15 & $1.46-6.79$ & 0.003 & 21.29 & $4.31-105.22$ & $<0.001$ \\
\hline $\begin{array}{l}\text { Resides with } \\
\text { friends/lives alone }\end{array}$ & 1.51 & $0.83-2.76$ & 0.184 & & & \\
\hline Income & 1.01 & $0.96-1.06$ & 0.727 & & & \\
\hline Parent drinks & 2.39 & $1.22-4.68$ & 0.011 & & & \\
\hline $\begin{array}{l}\text { Other family } \\
\text { member drinks }\end{array}$ & 2.05 & $1.07-3.94$ & 0.031 & & & \\
\hline Close friend drinks & 7.42 & $3.85-14.31$ & $<0.001$ & & & \\
\hline Role model drinks & 1.38 & $0.66-2.88$ & 0.395 & & & \\
\hline $\begin{array}{l}\text { Ever attended } \\
\text { formal school }\end{array}$ & & & & 17.18 & $1.27-232.13$ & 0.032 \\
\hline Knowledge score & & & & 0.95 & $0.79-1.15$ & 0.614 \\
\hline Attitude score & 0.867 & $0.77-0.98$ & 0.025 & 0.78 & $0.68-0.93$ & 0.006 \\
\hline \multicolumn{7}{|l|}{$\begin{array}{l}\text { Motor park } \\
\text { location }\end{array}$} \\
\hline Obalende & 1 & & & 1 & & \\
\hline Ojota & 1.112 & $0.17-1.81$ & 0.709 & -0.556 & $0.171-1.806$ & 0.329 \\
\hline Ojuelegba & 1.850 & $0.07-0.65$ & 0.128 & 0.216 & $0.072-0.648$ & 0.006 \\
\hline Oshodi & 1.870 & $0.27-2.73$ & 0.112 & 0.855 & $0.268-2.731$ & 0.791 \\
\hline
\end{tabular}

$\mathrm{OR}=$ odds ratio $\mathrm{CI}=$ confidence interval

Alcohol intoxication occurs when the quantity of alcohol consumed produces impairment in mental and physical abilities. ${ }^{22}$ This might be associated with other indirect effects like personal injuries, road accidents, and unsafe sex. ${ }^{1}$ We found that a considerable proportion of these youth used alcohol just before sexual intercourse. While we did not assess the relationship between alcohol use and unsafe sexual practices, there is evidence elsewhere demonstrating the relationship between alcohol use and unsafe sexual practices. ${ }^{23}$ The dangers of alcohol intoxication may also be of public health concern because many of these youth work in the motor parks and may be illegally engaged in driving, posing a hazard not only to themselves but also the general public.

Previous studies have reported that young people who initiate drinking before the age of 14 years are more likely to experience alcohol dependence. ${ }^{24,25}$ Despite the legal restrictions in Nigeria on the sale of alcohol to children and young people below the age of 18 years, these laws may not be widely enforced. In Nigeria, it is common to see alcohol sold by hawkers or in kiosks in small sachets and bottles, within and around motor parks, without any form of regulation. This has serious implications, as many of the young people engaging in menial jobs in the motor parks spend a considerable amount of time in environments where alcohol is easily accessible and where violations of sales restriction laws may be rife. There is therefore a need to develop a national bill that focuses on evidence-based population-wide interventions to address the problem of alcohol drinking in Nigeria. This bill should take into consideration the protection of these young people in MMJ VOL 28 (1): March 2016 
vulnerable environments, such as motor parks and garages.

While many of the participants in this study identified themselves as current drinkers during the data collection period, a substantial proportion desired to quit drinking but had tried unsuccessfully to do so. In an LMIC like Nigeria, with many competing health priorities, alcohol dependence treatment is often not considered a public health priority, and few centres are available to provide professional support for alcohol drinkers who want to quit. Furthermore, professional help might not be accessible to these young people, as evidenced by the majority of the respondents who had attempted to cut down on their drinking but received no assistance at all, or assistance from unqualified sources, such as family and friends.

Many of the study participants were aware of the potential dangers of alcohol use. This is not surprising, as knowledge does not necessarily equate with healthy behaviour. ${ }^{26}$ In designing strategies to reduce alcohol use among the youth population, efforts should go beyond merely providing information but should include creating the physical, social, and political environments conducive for behavioural change. If appropriately engaged, young people might be in a position to lend their voices to support and implement some aspects of alcohol policy.

Consistent with studies among young people in formal school settings, being male, and parental or peer drinking were associated with alcohol use. ${ }^{7,20,27-30}$ Additionally, being male and having attended formal schooling were factors associated with previous alcohol intoxication. In Nigeria, it has already been established that alcohol use is more common among males. ${ }^{5}$ It was surprising, however, to note that respondents who had been enrolled in formal school settings were more likely to have been intoxicated. While we did not assess their previous school environments and the possible influence of these environments on alcohol use, it is possible that school-level factors might have played a role in our findings. ${ }^{31}$ We also observed that alcohol consumption patterns might be site-specific, as respondents in Ojuelegba Motor Park were more likely to have been intoxicated. While we did not assess site-specific variances in alcohol availability and sales, it is possible that there might have been some variances among the sites, which could explain this finding. A similar study in Calabar, Cross River State, Nigeria, among bus drivers in motor parks also revealed high levels of alcohol consumption, suggesting that the location of the study might be contributory. ${ }^{32}$ Further research is needed to determine the influence of the characteristics of different motor parks on drinking behaviours in these environments.

\section{Study limitations}

This study has some limitations. First, the data were selfreported and were not validated biochemically; however, self-report has been shown to be a valid means of assessing alcohol use. ${ }^{29}$ Second, just prior to data collection, a law was passed in Lagos State banning individuals less than 18 years of age from congregating in motor parks, which undoubtedly affected the age distribution of the participants in this study. Also, the cross-sectional design does not allow for causal inferences. Another limitation was that the study was carried out in only one state of Nigeria, and the findings may be different form other states in Nigeria or other LMICs with different policies on alcohol use.

\section{Conclusions}

Alcohol use was a problem among the young people interviewed for this study and intoxication was common. Many of them desired to reduce their alcohol consumption but had received little professional help to do so. Males were more likely to consume alcohol and to have been intoxicated in the recent past. In designing programmes to combat the problems of alcohol use in Nigeria, specific efforts should be tailored towards young people. It might also be worthwhile to engage the NURTW leaders and other leaders of motor parks in Nigeria to help curb the problem of alcohol use among youth in motor parks.

\section{References}

1. World Health Organization. Alcohol fact sheet [Internet]. Geneva: World Health Organization; 2015 [cited 2015 Jan]. Available from: http://www.who.int/mediacentre/factsheets/fs349/en/.

2. National Institute of Alcohol Abuse and Alcoholism (NIAAA). National epidemiological survey on alcohol and related conditions 2007 [Internet]. Bethesda, MD, USA: National Institute of Alcohol Abuse and Alcoholism; [cited 2013 Apr]. Available from: http://www. niaaa.nih.gov/research/nesarc-iii.

3. Dumbili EW. Changing patterns of alcohol consumption in Nigeria: an exploration of responsible factors and consequences. Medical Sociology Online. 2013 Feb;7(1):20-33.

4. Adeyemo DA. Interpersonal factors as correlates of alcohol use among secondary school adolescents in Oyo State, Nigeria. Anthropologist. 2007;9(4):321-6.

5. World Health Organization. Country Profiles, African Region: Nigeria [Internet]. In: World Health Organization. Global status report on alcohol 2004. Geneva: World Health Organization; 2004 [cited 2004 Feb]. Available from: http://www.who.int/substance abuse/ publications/en/nigeria.pdf.

6. Akpata ES, Adeniyi AA, Enwonwu CO, Adeleke OA, Otoh EC. Association between alcohol consumption and periodontal disease among older Nigerians in plateau state: a preliminary study. Gerodontology. 2014 Dec 1. doi: 10.1111/ger.12173.

7. Atilola O, Stevanovic D, Balhara YP, Avicenna M, Kandemir H, Knez $\mathrm{R}$, et al. Role of personal and family factors in alcohol and substance use among adolescents: an international study with focus on developing countries. J Psychiatr Ment Health Nurs. 2014 Sep;21(7):609-17. doi: 10.1111/jpm. 12133 .

8. Merriam-Webster dictionary and thesaurus [Internet]. youth. [cited 2013 Jul]. Available from: http://www.merriam-webster.com/ dictionary/youth.

9. United Nations Educational, Scientific and Cultural Organization (UNESCO). What do we mean by "youth"? [Internet]. Paris: United Nations Educational, Scientific and Cultural Organization [cited 2013 Jul]. Available from: http://www.unesco.org/new/en/social-and-humansciences/themes/youth/youth-definition/.

10. Grunbaum JA, Kann L, Kinchen S, Ross J, Hawkins J, Lowry R, et al. Youth risk behavior surveillance--United States, 2003. MMWR Surveill Summ. 2004 May 21;53(2):1-96.

11. Connecticut Department of Labor. Clarification of the definition of out-of- school youth [memo] [Internet]. Wethersfield, CT, USA: Connecticut Department of Labor; 2006 [cited 2010 Jul 15]. Available from: http://www.ctdol.state.ct.us/wia/memos/2006/ap06-05.htm.

12. Adebiyi AO, Faseru B, Sangowawa AO, Owoaje ET. Tobacco use amongst out of school adolescents in a Local Government Area in Nigeria. Subst Abuse Treat Prev Policy. 2010 Oct 18;5:24. doi: 10.1186/1747-597X-5-24.

13. United Nations Educational, Scientific and Cultural Organization (UNESCO) and United Nations Children's Emergency Fund (UNICEF). Global initiative on out-of-school children: Nigeria country study- 
conducted within the conceptual and methodology framework (CMF) [Internet]. Paris: United Nations, Educational, Scientific and Cultural Organization; 2012 [cited 2015 Jan]. Available from: http://www. uis.unesco.org/Library/Documents/out-of-school-children-nigeriacountry-study-2012-en.pdf.

14. Oye-Adeniran BA, Aina OF, Gbadegesin A, Ekanem EE. Substance use and sexual behaviour among female students in Nigerian universities. Int Q Community Health Educ. 2014;35(1):73-83. doi: 10.2190/IQ.35.1.f.

15. Esan O, Makanjuola V, Oladeji B, Gureje O. Determinants of transition across the spectrum of alcohol use and misuse in Nigeria. Alcohol. 2013 May;47(3):249-55. doi: 10.1016/j.alcohol.2012.12.011.

16. Oshodi OY, Aina OF, Onajole AT. Substance use among secondary school students in an urban setting in Nigeria: prevalence and associated factors. Afr J Psychiatry (Johannesbg). 2010 Mar;13(1):52-7.

17. Medhi GK, Hazarika HC, Mahanta J. Tobacco and alcohol use among the youth of the agricultural tea industry in Assam, India. Southeast Asian J Trop Med Public Health. 2006 May;37(3):581-6.

18. Ewing JA. Detecting alcoholism. The CAGE questionnaire. JAMA. 1984 Oct 12;252(14):1905-7.

19. World Health Organization. Management of substance abuse [Internet]. Geneva: World Health Organization. Available from: http:// www.who.int/substance_abuse/en/.

20. Salary Explorer. Nigeria salaries [Internet]. [cited 2016 Jan]. Available from: http://www.salaryexplorer.com/salaries. php?\&loctype $=1 \&$ loc $=158$.

21. Olumide AO, Robinson AC, Levy PA, Mashimbye L, Brahmbhatt H, Lian Q, et al. Predictors of substance use among vulnerable adolescents in five cities: findings from the well-being of adolescents in vulnerable environments study.

22. J Adolesc Health. 2014 Dec;55(6 Suppl):S39-47. doi: 10.1016/j. jadohealth.2014.08.024.

23. World Health Organization. Acute intoxication [Internet]. In: World Health Organization. Management of substance abuse. Geneva: World Health Organization. [cited 2014 Dec]. Available from http://www. who.int/substance_abuse/terminology/acute_intox/en/.

24. World Health Organization. Global status report on alcohol and health 2014 [Internet]. Geneva: World Health Organization; 2014 [cited 2014 Dec]. Available from: www.who.int/iris/ bitstream/10665/112736/1/9789240692763 eng.pdf.

25. Hingson RW, Heeren T, Winter MR.Age at drinking onset and alcohol dependence: age at onset, duration, and severity. Arch Pediatr Adolesc Med. 2006 ;160:739-46.

26. DeWit DJ, Adlaf EM, Offord DR, Ogborne AC. Age at first alcohol use: a risk factor for the development of alcohol disorders. Am J Psychiatry. 2000 May;157(5):745-50.

27. Rimer BK, Glanz K. Theory at a glance: a guide for health promotion practice. Edited by National Institutes of Health. 2nd ed. Washington, D.C.: U.S. Department of Health and Human Services, National Institutes of Health; 2005.

28. Abayomi O, Onifade PO, Adelufosi AO, Akinhanmi AO. Psychosocial correlates of hazardous alcohol use among undergraduates in southwestern Nigeria. Gen Hosp Psychiatry. 2013 MayJun;35(3):320-4. doi: 10.1016/j.genhosppsych.2012.11.014.

29. Bello S, Fatiregun A, Ndifon WO, Oyo-Ita A, Ikpeme B. Social determinants of alcohol use among drivers in Calabar. Niger Med J. 2011 Oct;52(4):244-9. doi: 10.4103/0300-1652.93797.

30. Wood MD, Read JP, Mitchell RE, Brand NH. Do parents still matter? Parent and peer influences on alcohol involvement among recent high school graduates. Psychol Addict Behav. 2004 Mar;18(1):19-30.

31. Onya H, Tessera A, Myers B, Flisher A. Adolescent alcohol use in rural South African high schools. Afr J Psychiatry (Johannesbg). 2012 Sep;15(5):352-7. doi: http://dx.doi.org/10.4314/ajpsy.v15i5.44.

32. Mrug S, Gaines J, Su W, Windle M. School-level substance use: effects on early adolescents' alcohol, tobacco, and marijuana use. J Stud Alcohol Drugs. 2010 Jul;71(4):488-95. 